\title{
Heregulin- $\beta 1$ Activates NF-E2-related Factor 2 and Induces Manganese Superoxide Dismutase Expression in Human Breast Cancer Cells via Protein Kinase B and Extracellular Signal-regulated Protein Kinase Signaling Pathways
}

\author{
Ji-Young Park', Soma Saeidi, ${ }^{1,2}$ Eun-Hee $\mathrm{Kim}^{3}$, Do-Hee Kim ${ }^{4}$, Hye-Kyung Na ${ }^{5}$, Joo-Seob Keum ${ }^{6,7}$, \\ Young-Joon Surh ${ }^{1,2}$ \\ ${ }^{1}$ Tumor Microenvironment Global Core Research Center, College of Pharmacy, Seoul National University, Seoul, ${ }^{2}$ Department of \\ Molecular Medicine and Biopharmaceutical Sciences, Graduate School of Convergence Science and Technology, Seoul National \\ University, Seoul, ${ }^{3}$ College of Pharmacy and Institute of Pharmaceutical Sciences, CHA University, Seongnam, ${ }^{4}$ Department \\ of Chemistry, College of Convergence and Integrated Science, Kyonggi University, Suwon, ${ }^{5}$ Department of Food Science and \\ Biotechnology, College of Knowledge-Based Services Engineering, Sungshin Women's University, Seoul, Korea, ${ }^{6}$ Medical \\ University of South Carolina, Charleston, SC, USA, ${ }^{7}$ Department of Pathology, Kangbuk Samsung Hospital, Sungkyunkwan \\ University School of Medicine, Seoul, Korea
}

\begin{abstract}
Heregulin- $\beta 1$, a ligand of ErbB-2 and ErbB-3/4 receptors, has been reported to potentiate oncogenicity and metastatic potential of breast cancer cells. In the present work, treatment of human mammary cancer (MCF-7) cells with heregulin- $\beta 1$ resulted in enhanced cell migration and expression of manganese superoxide dismutase (MnSOD) and its mRNA transcript. Silencing of MnSOD abrogated clonogenicity and migrative ability of MCF-7 cells. Heregulin- $\beta 1$ treatment also increased nuclear translocation, antioxidant response element binding and transcriptional activity of NF-E2-related factor 2 (Nrf2). A dominant-negative mutant of $\mathrm{Nrf2}$ abrogated heregulin- $\beta 1$-induced MnSOD expression. Treatment with heregulin- $\beta 1$ caused activation of protein kinase B (Akt) and extracellular signal-regulated protein kinase (ERK). The pharmacological inhibitors of phosphatidylinositol 3-kinase and mitogen-activated protein kinase kinase $1 / 2$, which are upstream of Akt and ERK, respectively, attenuated heregulin- $\beta 1$-induced $\mathrm{Mn}$ SOD expression and nuclear localization of Nrf2. In conclusion, heregulin-1 induces upregulation of MnSOD and activation of Nrf2 via the Akt and ERK signaling in MCF-7 cells, which may confer metastatic potential and invasiveness of these cells.
\end{abstract}

Key Words Breast cancer, Heregulin- $\beta 1$, Manganese superoxide dismutase, NF-E2-related factor 2

\section{INTRODUCTION}

The epidermal growth factor receptor (EGFR) family of receptor tyrosine kinases are frequently overexpressed in human cancers and responsible for tumor cell proliferation, survival, adhesion, migration and differentiation [1]. Heregulin- $\beta 1$ also known as neuregulin-1 (NRG-1) is a member of the EGF family of growth factors and acts as a ligand for ErbB family receptor tyrosine kinases [2]. The heregulin family of growth factors includes at least fifteen distinct proteins derived from differential splicing of the RNA of a single gene. Most heregulin proteins are soluble, secreted $44-\mathrm{kDa}$ glycoproteins originating from transmembrane precursors, undergoing typical glycosylation and trafficking [3]. Among these, heregulin- $\beta 1$ is known as the most potent form which is able to activate ErbB-2 indirectly through binding to ErbB3 or ErbB4.

It has been shown that overexpression or aberrant expression of the ErbB receptor family proteins could cause antiestrogen resistance [4]. In addition, heregulin is involved in progression and metastatic potential of breast cancer

Received January 5, 2021, Revised February 6, 2021, Accepted February 15, 2021 
[2]. Heregulin- $\beta 1$ was reported to activate matrix metalloproteinase-9 (MMP-9) [5], which was regulated by multiple signaling pathways such as extracellular signal-regulated protein kinase (ERK), p38, and protein kinase C (PKC) [5]. Heregulin- $\beta 1$ overcame the inhibitory effects of gefitinib on growth and invasiveness of tamoxifen-resistant Michigan Cancer Foundation-7 (MCF-7) cells by promoting ErbB-2/ ErbB-3 heterodimerization and activation of phosphatidylinositol 3-kinase (PI3K)/protein kinase B (Akt) [6]. Moreover, heregulin- $\beta 1$ was found to induce angiopoietin-2 (Ang-2) up-regulation via the Akt and ERK signaling in human breast cancer cell lines [7]. Immunohistochemical analysis of ErbB2 and Ang-2 in human breast carcinomas has revealed that Ang-2 expression in breast cancer correlates with ErbB-2 expression [7]. Heregulin- $\beta 1$ enhanced aggregation of MCF-7 cells by activating PI3K [8]. Heregulin- $\beta 1$ up-regulates VEGF $C$, a critical activator of tumor lymphangiogenesis that has been strongly implicated in the tumor metastasis [9] and also urokinase plasminogen activator which is serine proteinase involved in the destruction of extracellular matrix separated from the epithelial and stromal compartments [10]. However, in order to better clarify the precise role of heregulin- $\beta 1$, it is still important to identify its new downstream effector molecules.

Aberrant production of mitochondrial reactive oxygen species (ROS) can have dramatic effects on cellular function, in part, due to oxidative modification of key metabolic proteins localized in the mitochondrion. Manganese superoxide dismutase (MnSOD) is the major ROS detoxifying enzyme localized in the mitochondria. During the electron transport in the respiratory chain assembly of mitochondria, substantial amounts of superoxide are generated as an obligatory byproduct [11]. In this context, MnSOD plays a pivotal role in cellular antioxidant defence to combat deleterious ROS produced in mitochondria.

The role of MnSOD in protecting carcinogenesis associated with oxidative damage has been extensively investigated and well-documented [12-14]. It has been reported that overexpression of MnSOD ameliorates the malignant phenotype of human breast cancer cells [15]. However, some of recent studies have shown that MnSOD stimulates proliferation and metastatic potential of certain cancer cells [16-20] and also confers drug resistance against anti-cancer therapies $[21,22]$. In the present study, we found the possible association of heregulin- $\beta 1$-induced MnSOD expression with oncogenic properties of the human breast cancer cells (MCF-7).

\section{MATERIALS AND METHODS}

\section{Materials}

Heregulin- $\beta 1$ was purchased from Lab Vision (Fremont, CA, USA). RPMI 1640 medium, fetal bovine serum, and penicillin/ streptomycin/fungizone mixture were obtained from Gibco BRL (Grand Island, NY, USA). M-MLV reverse transcriptase and the luciferase assay system with reporter lysis buffer were supplied by Promega (Madison, WI, USA). $\left[\gamma^{3}{ }^{32} \mathrm{P}\right]$ ATP was the product of NEN Life Science (Boston, MA, USA). Anti-Akt and anti-P-Akt were provided from Cell Signaling Technology (Beverly, MA, USA). anti-ERK, anti-P-ERK, and anti-Nrf2 were obtained from Santa Cruz Biotechnology Inc. (Santa Cruz, CA, USA). An antibody against MnSOD was supplied by Stressgen Biotechnologies (Victoria, BC, Canada). Secondary antibodies were purchased from Zymed Laboratories Inc. (San Francisco, CA, USA). LY294002 and U0126 were supplied by Calbiochem (San Diego, CA, USA) and Tocris (Ellisville, MO, USA), respectively. The reporter gene fusion construct for human antioxidant response elements (ARE), GC-mutant ARE, as well as control plasmid pEF were kindly provided by Dr. Jeffery A. Johnson (University of Wisconsin-Madison, Madison, WI, USA). Hemaglutinin-tagged full-length Akt (HA-Akt) and kinase-dead Akt (KD-Akt) were kindly provided by Dr. An-Sik Chung (Korea Advanced Institute of Science and Technology, Daejeon, Korea).

\section{Cell culture}

The MCF-7 cells were maintained at $37^{\circ} \mathrm{C}$ in a humidified atmosphere of $5 \% \mathrm{CO}_{2} / 95 \%$ air in RPMI medium supplemented with $10 \%$ fetal bovine serum and $100 \mathrm{ng} / \mathrm{mL}$ penicillin/ streptomycin/fungizone mixture. Cells were grown to $60 \%$ to $80 \%$ confluence and trypsinized with $0.05 \%$ trypsin containing $2 \mathrm{mM}$ EDTA. Cells were plated at an appropriate density according to an each experimental scale. Twenty four hours in advance, cells were switched to serum-free RPMI for treatment.

\section{Colony forming and migration assays}

MCF-7 cells, treated with negative control and MnSOD siRNA (Ambion, Inc., Austin, TX, USA), were plated in 6-well plates at a density of 150 cells per well. The RPMI was changed every other day. After one week of incubation, the colonies were fixed in cold methanol and stained by $0.5 \%$ crystal violet for 1 hour. The stained colonies were washed with double distilled water (DDW) to remove the excess dye. For the migration assay, MCF-7 cells were transfected with control and MnSOD siRNA. After 48 -hour incubation at $37^{\circ} \mathrm{C}$, the cells were seeded onto Culture-Inserts ${ }^{\circledR}$ (ibidi, Regensburg, Germany) to generate a wound gap. After additional incubation for 24 hours, the insert was gently removed. The progression of wound closure was visualized at 24 hours under the microscope.

\section{Reverse transcriptase-polymerase chain reaction (RT-PCR)}

Total RNA was isolated from MCF-7 cells using TRIzol ${ }^{\circledR}$ reagent (Invitrogen, Carlbad, CA, USA) according to the manufacturer's instructions. RT-PCR was performed following standard procedures. PCR conditions for MnSOD and for the 
house-keeping gene, glyceraldehyde-3-phophate dehydrogenase (GAPDH) were as follow: $M n S O D, 27$ cycles of $94^{\circ} \mathrm{C}$ for 1 minute; $55^{\circ} \mathrm{C}$ for 2 minutes; $72^{\circ} \mathrm{C}$ for 3 minutes, $G A P D H$, 26 cycles of $94^{\circ} \mathrm{C}$ for 1 minute; $56^{\circ} \mathrm{C}$ for 2 minutes; $72^{\circ} \mathrm{C}$ for 2 minutes. The pairs of primers were as follows (forward and reverse, respectively): MnSOD, 5'-CCT GAA CGT CAC CGA GGA GAA G-3' and 5'-CTC CCA GTT GAT TAC ATT AGT-3'; GAPDH, 5'-AAG GTC GGA GTC AAC GGA TTT-3' and 5'GCA GTG AGG GTC TCT CTC CCT-3'.

Amplification products were resolved by $1.0 \%$ agarose gel electrophoresis, stained with ethidium bromide, and photographed under ultraviolet light. Primers were purchased from Bionics (Seoul, Korea).

\section{Western blot analysis}

After treatment, MCF-7 cells were washed with PBS and mixed with lysis buffer (50 mM Tris- $\mathrm{HCl}, \mathrm{pH}$ 8.0, 2 mM EDTA, $1 \%$ Triton $\mathrm{X}-100$ with a protease inhibitor cocktail tablet) for 15 minutes on ice followed by centrifugation at $12,000 \mathrm{~g}$ for 15 minutes. The protein concentration of the supernatant was measured by using the bicinchoninic acid (BCA) reagents (Pierce, Rockford, IL, USA). Protein samples (50 $\mu \mathrm{g}$ ) were loaded to SDS-PAGE gel and transferred to the polyvinylidene difluoride (PVDF) membrane (Gelman Laboratory, Ann Arbor, MI, USA). The blots were blocked for 1 hour at room temperature in fresh blocking buffer $(0.1 \%$ Tween-20 in PBS containing $5 \%$ non-fat dry milk). Dilutions of primary antibodies were made in PBS with 3\% non-fat dry milk, and blots were incubated at $4^{\circ} \mathrm{C}$. Following three washes with PBST, the blots were incubated with horseradish peroxidase-conjugated secondary antibodies in PBS with 3\% non-fat dry milk for 1 hour at room temperature. The blots were washed again three times in PBST buffer, and transferred proteins were incubated with ECL substrate solution (Amersham Pharmacia Biotech Inc., Piscataway, NJ, USA) for 1 minute according to the manufacturer's instructions and visualized with $\mathrm{X}$-ray film.

\section{MnSOD assay}

SOD activity was measured by modification of an indirect inhibition assay developed by Spitz and Oberley [23,24]. Xanthine-xanthine oxidase was utilized to generate a superoxide flux. The nitroblue tetrazolium (NBT) reduction by $\mathrm{O}_{2}$ - to blue formazon was monitored at $560 \mathrm{~nm}$ at a room temperature. The assay mixture also contained catalase to remove $\mathrm{H}_{2} \mathrm{O}_{2}$ and diethylenetriaminepentaacetic acid (DETAPAC) to chelate metal ions which may interfere with the assay system by stimulating the redox cycling. Sodium cyanide ( $\mathrm{NaCN}, 5$ $\mathrm{mM}$ ) was added (for 45 to 50 minutes) to assess the MnSOD activity. As sodium cyanide inhibits $\mathrm{Cu} / \mathrm{ZnSOD}$, the remaining activity measured in the cells in the presence of $\mathrm{NaCN}$ reflects only MnSOD activity. Each one-mL assay mixture contained the final concentration of following reagents: 50 $\mathrm{mM}$ potassium phosphate buffer $(\mathrm{pH} 7.8), 1 \mathrm{mM}$ DETAPAC, $56 \mu \mathrm{M}$ NBT, $0.1 \mathrm{mM}$ xanthine, 0.05 unit xanthine oxidase,
MnSOD standard and $330 \mu \mathrm{g}$ protein sample.

\section{Immunofluorescent analysis of MnSOD}

Cells were plated on the chamber slide and treated with heregulin- $\beta 1$. After fixation with paraformaldehyde, samples were incubated with blocking agents $(0.1 \%$ Tween- 20 in PBS containing $5 \%$ bovine serum albumin), washed with PBS and then incubated with a diluted (1:100) primary antibody for overnight. After washing with PBS, samples were incubated with a fluorescein isothiocyanate (FITC)-conjugated secondary antibody for 1 hour and examined under a confocal microscope (Leika, Germany).

\section{Preparation of nuclear proteins}

After treatment with heregulin- $\beta 1$, cells were washed with icecold PBS, scraped in $1 \mathrm{~mL}$ PBS and centrifuged at 12,000 $g$ for 30 seconds at $4^{\circ} \mathrm{C}$. Pellets were suspended in $200 \mu \mathrm{L}$ of hypotonic buffer A (10 mM HEPES, pH 7.8, $10 \mathrm{mM} \mathrm{KCl,} 2$ $\mathrm{mM} \mathrm{MgCl} 2,1 \mathrm{mM}$ dithiothreitol [DTT], $0.1 \mathrm{mM}$ EDTA and 0.1 $\mathrm{mM}$ phenylmethylsulfonyl fluoride [PMSF]) for 15 minutes on ice, and $12.5 \mu \mathrm{L}$ of $10 \%$ Nonidet P-40 solution was added for 5 minutes. The mixture was centrifuged for 6 minutes at $12,000 \mathrm{~g}$. Supernatant was kept for Western blot analysis. The nuclei were washed once with $400 \mu \mathrm{L}$ of PBS, suspended in $70 \mu \mathrm{L}$ of buffer $\mathrm{C}$ (50 mM HEPES, pH 7.8, $50 \mathrm{mM} \mathrm{KCl}$, $300 \mathrm{mM} \mathrm{NaCl}, 0.1 \mathrm{mM}$ EDTA, $1 \mathrm{mM}$ DTT, $0.1 \mathrm{mM}$ PMSF and $10 \%$ glycerol) for 20 minutes on ice and centrifuged for 6 minutes at $12,000 \mathrm{~g}$. The supernatant containing nuclear proteins was collected and stored at $-70^{\circ} \mathrm{C}$ after determination of the protein concentration.

\section{Electrophoretic mobility shift assay}

Synthetic double strand oligonucleotide containing the Nrf2 binding domain (ARE) was labeled with $\left[\gamma-{ }^{32} \mathrm{P}\right]$ ATP by T4 polynucleotide kinase and purified on a Nick column (Amersham Pharmacia Biotech, Buckinghamshire, UK). The binding reaction was carried out in a total volume of $25 \mu \mathrm{L}$ containing $10 \mathrm{mM}$ Tris- $\mathrm{HCl}$ (pH 7.5), $100 \mathrm{mM} \mathrm{NaCl}, 1 \mathrm{mM}$ DTT, 1 $\mathrm{mM}$ EDTA, $4 \%$ glycerol, $0.1 \mathrm{mg} / \mathrm{mL}$ sonicated salmon sperm DNA, $10 \mu \mathrm{g}$ of nuclear extracts and $100,000 \mathrm{cpm}$ of the labeled probe. An 100-fold excess of unlabeled oligonucleotide (competitor) was added where necessary. After 50-minute incubation at room temperature, $2 \mu \mathrm{L}$ of $0.1 \%$ bromophenol blue was added, and samples were electrophoresed through a $6 \%$ non-denaturating polyacrylamide gel at $150 \mathrm{~V}$ for 2 hours. Finally, the gel was dried and exposed to X-ray film.

\section{Transient transfection and the reporter gene assay}

MCF-7 cells were plated at a confluence of $50 \%$ density in 6 -well plate and grown in RPMI supplemented with $10 \%$ heat-inactivated fetal bovine serum at $37^{\circ} \mathrm{C}$ in a humidified atmosphere of $5 \% \mathrm{CO}_{2} / 95 \%$ air. Transient transfections were performed using the $\mathrm{N}$-[1-(2,3-dioleolloxy)pro- 
pyl]- $N, N, N$-trimethylammoniummethylsulfate (DOTAP) liposomal transfection reagents according to the instructions supplied by the manufacturer (Roche Molecular Biochemicals, Mannheim, Germany). After 8- to 12-hour transfection, cells were treated with heregulin- $\beta 1$ for additional 8 hours, and the cell lysis was carried out with the reporter lysis buffer. After mixing the cell extract with a luciferase substrate (Promega), the luciferase activity was measured by the luminometer (AntoLumat LB 953; EG\&G Berthold, Bad Widbad, Germany). The $\beta$-galactosidase assay was done according to the supplier's instructions (Promega $\beta$-Galactosidase Enzyme Assay System) for normalizing the luciferase activity.

\section{Public data resources}

Coexpression and clinical data from The Cancer Genome Atlas (TCGA) were analyzed using the cBioportal web interface (http://www.cbioportal.org) including RNA-seq gene expression profile, and correlation plots with Spearman's correla- tions are presented.

\section{Statistical analysis}

When necessary, data were expressed as means \pm SD of at least three independent experiments, and statistical analysis for single comparison was performed using the Student's $t$-test. The criterion for statistical significance was $P<0.05$.

\section{RESULTS}

\section{Heregulin- $\beta 1$ stimulates the migration of MCF-7 cells}

Treatment with hregulin- $\beta 1(50 \mathrm{ng} / \mathrm{mL})$ for 24 hours enhanced the migrative capability of MCF-7 cells (Fig. 1A). In order to figure out the clinical relevance of heregulin- $\beta 1$ to human breast cancer progression, we intended to identify its potential target molecule. For this purpose, we analyzed the correlation between NRG1 (Heregulin- $\beta 1$ gene) and each of the
A
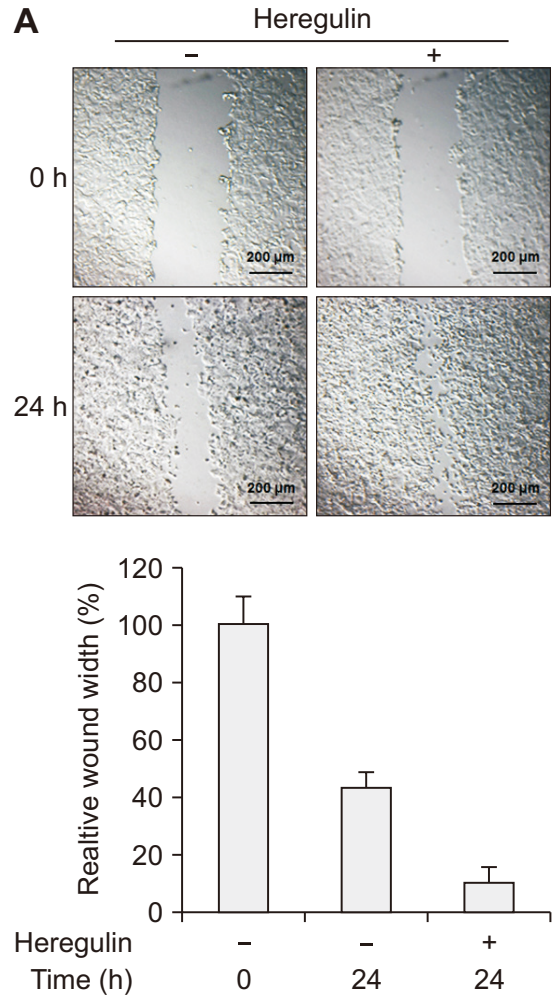

B

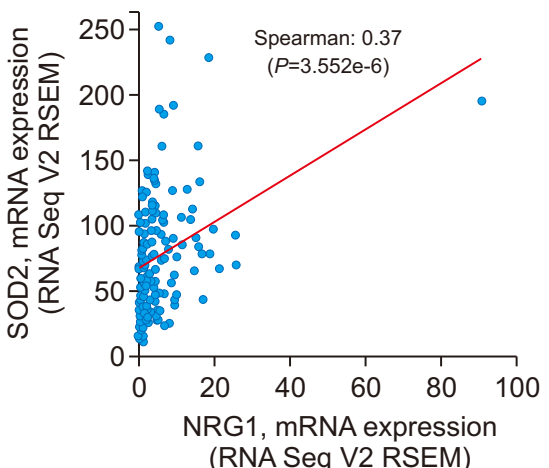

C

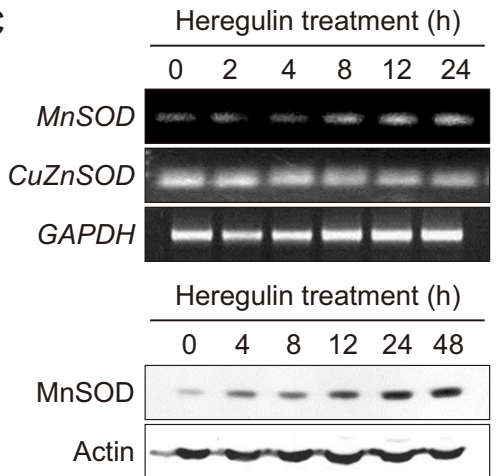

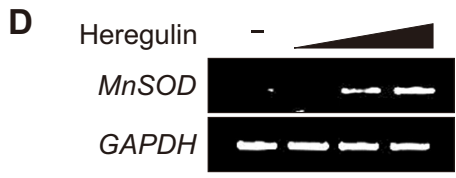

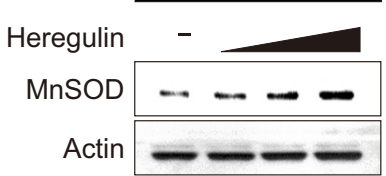

E

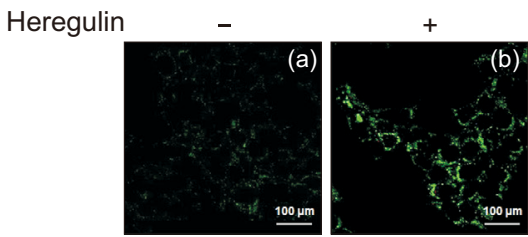

$\mathbf{F}$

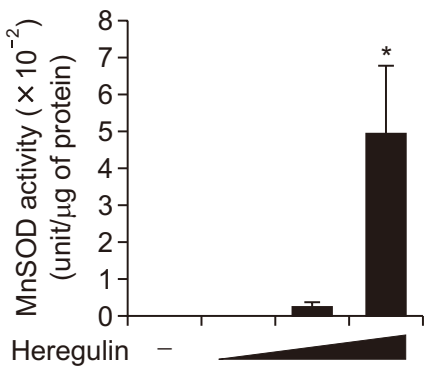

Figure 1. Heregulin- $\beta 1$ stimulates the migration of MCF-7 cells and induces expression of manganese superoxide dismutase (MnSOD). (A) MCF-7 cells were treated with heregulin- $\beta 1$ for 24 hours and subjected to the wound healing assay. (B) mRNA expression correlation data between neuregulin-1 (NRG1) and MnSOD in the metastatic breast cancer (TCGA provisional) were obtained by using the cBioportal web interface. (C) MCF-7 cells were treated with heregulin- $\beta 1(50 \mathrm{ng} / \mathrm{mL})$ for indicated time periods. The expression of MnSOD mRNA and protein was measured by RT-PCR and Western blot analyses, respectively as described in Materials and Methods. (D). MCF-7 cells were treated with $0,1,10$, or 50 ng/ $\mathrm{mL}$ of heregulin- $\beta 1$ for 8 hours (for mRNA) and 24 hours (for protein). The expression of MnSOD mRNA and protein was measured by RT-PCR and Western blot analyses, respectively. (E) Immunocytochemical analysis was performed using an anti-MnSOD antibody after the treatment of MCF7 cells with $50 \mathrm{ng} / \mathrm{mL}$ heregulin- $\beta 1$ for 24 hours. Images of the cellular fluorescence were acquired using a confocal laser-scanning microscope as described under Materials and Methods; (a) Vehicle-control cells. (b) Cells treated with $50 \mathrm{ng} / \mathrm{mL}$ heregulin- $\beta 1$ for 24 hours. Scale bar, $100 \mu \mathrm{m}$. (F) MCF-7 cells treated with heregulin- $\beta 1(0,1,10$, or $50 \mathrm{ng} / \mathrm{mL})$ for 24 hours, and the catalytic activity of MnSOD was measured as described in Materials and Methods. *Significantly different from the control without heregulin- $\beta 1$ treatment $(P<0.05)$. 
upregulated genes in the metastatic breast cancer cohorts. There was a positive correlation between NRG1 and MMP1 or VEGF (Figure S1). NRG1 expression also correlates with MnSOD (Fig. 1B). Stimulation of MCF-7 cells with heregulin- $\beta 1$ resulted in enhanced expression of $M n S O D$, but did not influence the expression of CUSOD (Fig. 1C, upper panel). In parallel with elevated expression of the mRNA transcript, the protein levels of MnSOD were also increased in a time-dependent manner (Fig. 1C, lower panel). Treatment of cells with heregulin- $\beta 1(0,1,10$, and $50 \mathrm{ng} / \mathrm{mL})$ induced expression of MnSOD mRNA and protein in a concentration-dependent manner (Fig. 1D). To ascertain the induction of MnSOD by heregulin- $\beta 1$, we conducted an immunocytochemical analysis using the anti-MnSOD antibody. As illus- trated in Figure 1E, the cellular accumulation of MnSOD was evident in MCF-7 cells treated with heregulin- $\beta 1$. Next, we determined the effects of heregulin- $\beta 1$ on the catalytic activity of MnSOD. Thus, there was marked induction of MnSOD activity observed at 24 hours following treatment with 1,10 , or $50 \mathrm{ng} / \mathrm{mL}$ heregulin- $\beta 1$ (Fig. 1F).

\section{Heregulin- $\beta 1$ induces the expression of MnSOD via ERK and Akt signaling in MCF-7 cells}

To further clarify the possible upstream signaling pathway(s) involved in the heregulin- $\beta 1$-mediated MnSOD induction, we examined the activation of ERK and Akt, two major signaling enzymes involved in cell survival against oxidative stress. The pharmacologic inhibition of ERK (Fig. 2A) and Akt (Fig.
A

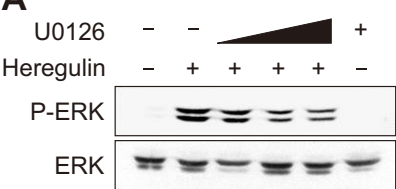

C
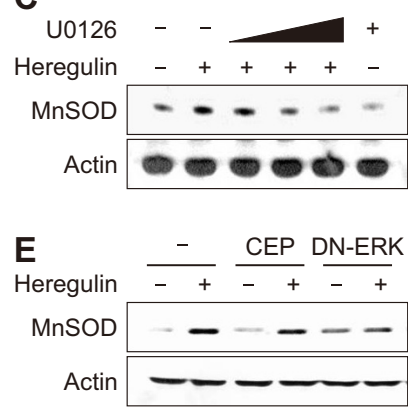

G

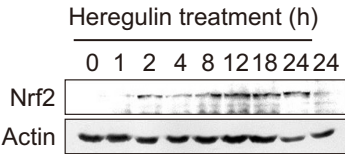

B

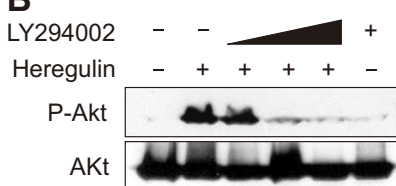

D

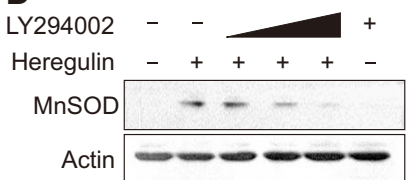

Feregulin $\frac{-}{-+} \frac{\text { HA-Akt KD-Akt }}{-++} \frac{\text { t }}{-+}$

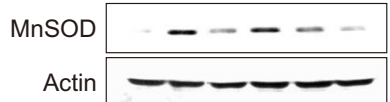

H

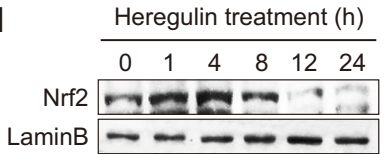

I

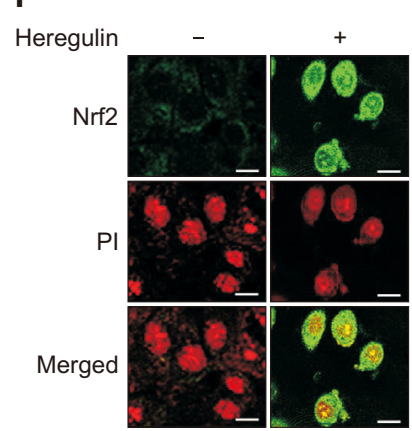

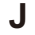

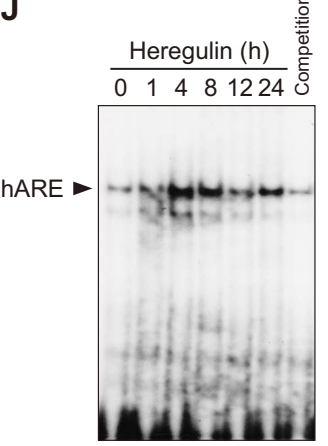

K

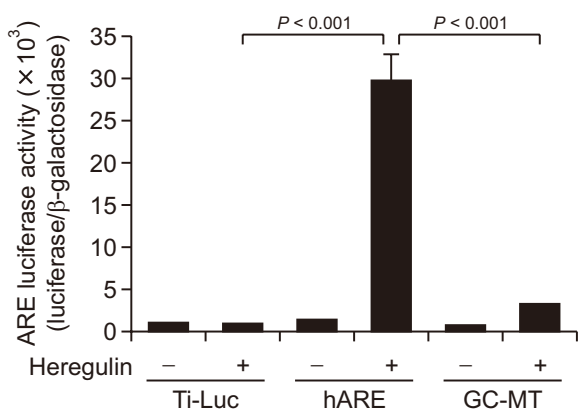

Figure 2. Heregulin- $\beta 1$ up-regulates manganese superoxide dismutase (MnSOD) expression through activation of extracellular signalregulated protein kinase (ERK) and protein kinase B (Akt), and activates NF-E2-related factor 2 (Nrf2). (A, B) MCF-7 cells were preincubated with $\mathrm{U} 0126(0,0.1,1$, or $5 \mu \mathrm{M})$ or LY294002 $(0,1,5$, or $20 \mu \mathrm{M})$ and exposed to heregulin- $\beta 1(50 \mathrm{ng} / \mathrm{mL})$ for 8 hours. The protein from cell lysates was resolved by SDS-PAGE and analyzed by Western blot analysis to measure the phosphoryation of ERK (A) or Akt (B). (C, D) The effects of pharmacologic inhibitors of ERK and Akt on expression of MnSOD were assessed by Western blot analysis after exposure to heregulin- $\beta 1$ for 24 hours. Treatment conditions and other detials are same as above. (E) MCF-7 cells were transfected transiently with dominant-negative (DN)-ERK or control plasmid (CEP). After transfected with each vectors for 12 hours using DOTAP reagent, MCF-7 cells were subjected to heregulin- $\beta 1$ treatment for $24 \mathrm{~h}$. The expression of MnSOD was monitored by Western blot analysis. (G) MCF-7 cells were transfected transiently with hemaglutinin-tagged full-length Akt (HA-Akt) or kinase-dead Akt (KD-Akt). After transfection with each vector for $12 \mathrm{~h}$ using DOTAP reagent, MCF-7 cells were treated with heregulin- $\beta 1$ for additional 24 hours. Proteins from cell lysates were resolved by SDS-PAGE and analyzed by Western blot analysis. (H) Nuclear extracts from MCF-7 cells were prepared after treatment with heregulin- $\beta 1(50 \mathrm{ng} / \mathrm{mL})$ for indicated time periods. Immunoblots of nuclear lysates from treated MCF-7 cells were probed with the Nrf2 specific antibody. (I) Immunocytochemical analysis was performed using anti-Nrf2 antibody after the treatment of MCF-7 cells with $50 \mathrm{ng} / \mathrm{mL}$ of heregulin- $\beta 1$ for 4 hours. Cells were stained with propidium iodide and analyzed by confocal microscopy. Scale bar, $50 \mu \mathrm{m}$. (J) Heregulin- $\beta 1$ induces DNA binding activity of Nrf2 in MCF-7 cells. MCF-7 cells were treated with heregulin- $\beta 1$ ( $50 \mathrm{ng} / \mathrm{mL})$ for indicated time periods. The DNA-binding activity of Nrf2 in MCF-7 cells stimulated with heregulin- $\beta 1$ was measured by electrophoretic mobility shift assay (EMSA). The nuclear extract isolated from heregulin- $\beta 1$-treated cells was used for EMSA as described under Materials and Methods. (K) The heregulin- $\beta 1$-mediated increase in the transcriptional activation of antioxidant response elements (ARE) was measured by the luciferase reporter gene assay. After overnight transfection, cells were exposed to $50 \mathrm{ng} / \mathrm{mL}$ heregulin- $\beta 1$ for 8 hours, and treated with reporter lysis buffer for the measurement of the luciferase activity. 
2B) with U0126 (MEK inhibitor) and LY294002 (PI3K inhibitor), respectively abrogated heregulin- $\beta 1$-induced MnSOD expression (Fig. 2C and 2D). To verify the role of ERK and Akt in the induction of MnSOD expression by heregulin- $\beta 1$, MCF-7 cells were transfected transiently with dominant-negative ERK (DN-ERK) or KD-Akt. Genetic inhibition of ERK and Akt signaling also abolished the expression of MnSOD induced by heregulin- $\beta 1$ (Fig. $2 \mathrm{E}$ and $2 \mathrm{~F}$ ).

\section{Heregulin- $\beta 1$ increases the nuclear}

\section{translocation and ARE binding activity of Nrf2}

Many studies on gene structures of various antioxidant enzymes have revealed the presence of the ARE sequence in their gene promoter regions [25]. This prompted us to examine the effects of heregulin- $\beta 1$ on the activation of Nrf2. Treatment of MCF- 7 cells with heregulin- $\beta 1$ induces time-dependent increase in the expression Nrf2 (Fig. 2G) and nuclear translocation (Fig. 2H). The nuclear localization of Nrf2 was also confirmed by the immunofluorescence staining (Fig. 2l). The heregulin- $\beta 1$-induced ARE-binding activity of Nrf2 peaked at 4 hours and gradually decreased thereafter (Fig. 2J). The specificity of ARE-binding activity of Nrf2 was verified by the competition assay using an excess of unlabeled ARE-oligonucleotide (Fig. 2J). To determine a potential inducing effect of heregulin- $\beta 1$ on Nrf2-dependent gene transcription, MCF-7 cells were transiently transfected with a reporter gene construct (ARE-Luc) containing the ARE binding site ligated to luciferase gene. When transfected cells were incubated with heregulin- $\beta 1$ for 8 hours, there was approximately a 30 fold increase in the Nrf2-ARE reporter gene activity (Fig. 2K). In addition, transient transfection with GC-MT-Luc, a construct containing a mutant form of the GC dinucleotide at the 3'-most end of the ARE core which is essential for ARE function, rendered the cells much less responsive to the heregulin- $\beta 1$-in- duced ARE reporter gene activity. To determine whether Nrf2ARE signaling is necessary for MnSOD expression, MCF7 cells were transiently transfected with a dominant negative Nrf2 (DN-Nrf2) construct or control vector (pEF). As ERK and Akt were involved in heregulin- $\beta 1$-induced SOD upregulation, we examined whether these kinases could mediate Nrf2 activation. Pharmacologic inhibition ERK and Akt abrogated the nuclear accumulation of Nrf2 (Fig. 3A and 3B). Further, functional knock out of Nrf2 by dominant negative gene mutation abrogated heregulin- $\beta 1$-induced MnSOD expression (Fig. $3 C)$. Taken together, these findings indicate that Akt and ERK are essential upstream enzymes responsible for inducing the expression of MnSOD by heregulin- $\beta 1$ via the Nrf2-ARE signaling.

\section{MnSOD plays a role in proliferation and migration of MCF-7 cells}

The involvement of MnSOD in MCF-7 cell growth and proliferation was evidenced by marked reduction in migration (Fig. 4A) and colony formation (Fig. 4B) by siRNA knockdown of SOD gene.

\section{DISCUSSION}

It is well known that transmission of intracellular signaling mediated by the human epidermal growth factor receptor (HER/ EGFR/ErbB) family of tyrosine kinase receptors (HER1/ EGFR, HER2/ErbB-2, HER3/ErbB-3, and HER4/ErbB-4) is involved in growth regulation of breast cancer cells. Her2/ ErbB-2 overexpression has been implicated in the pathogenesis and progression of breast cancer [26-28]. The growth factor heregulin, expressed in about $30 \%$ of breast cancer tumors, activates the ErbB-2 receptor via induction of heterodimeric complexes of ErbB-2 with ErbB-3 or ErbB-4 [27].

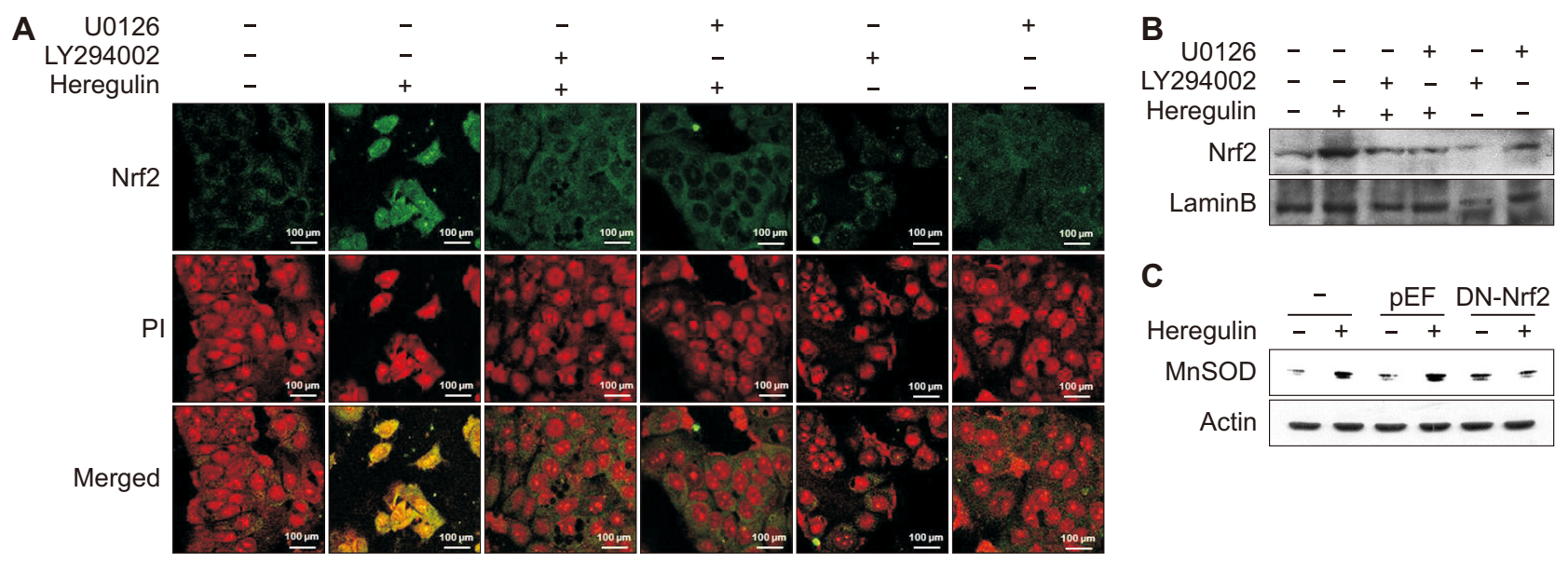

Figure 3. Heregulin- $\beta 1$-induced nuclear translocation of NF-E2-related factor 2 (Nrf2) is mediated by extracellular signal-regulated protein kinase (ERK) and protein kinase B (Akt). (A, B) MCF-7 cells were preincubated with U0126 (5 $\mu$ M) or LY294002 (20 $\mu$ M) and exposed to heregulin- $\beta 1$ ( $50 \mathrm{ng} / \mathrm{mL}$ ) for 8 hours for immunofluorescence $(A)$ and Western blot (B) analyses of Nrf2. Scale bar, $100 \mu \mathrm{m}$. (C) Effects of dominant negative mutant $\mathrm{Nrf} 2$ on manganese superoxide dismutase (MnSOD) expression. 

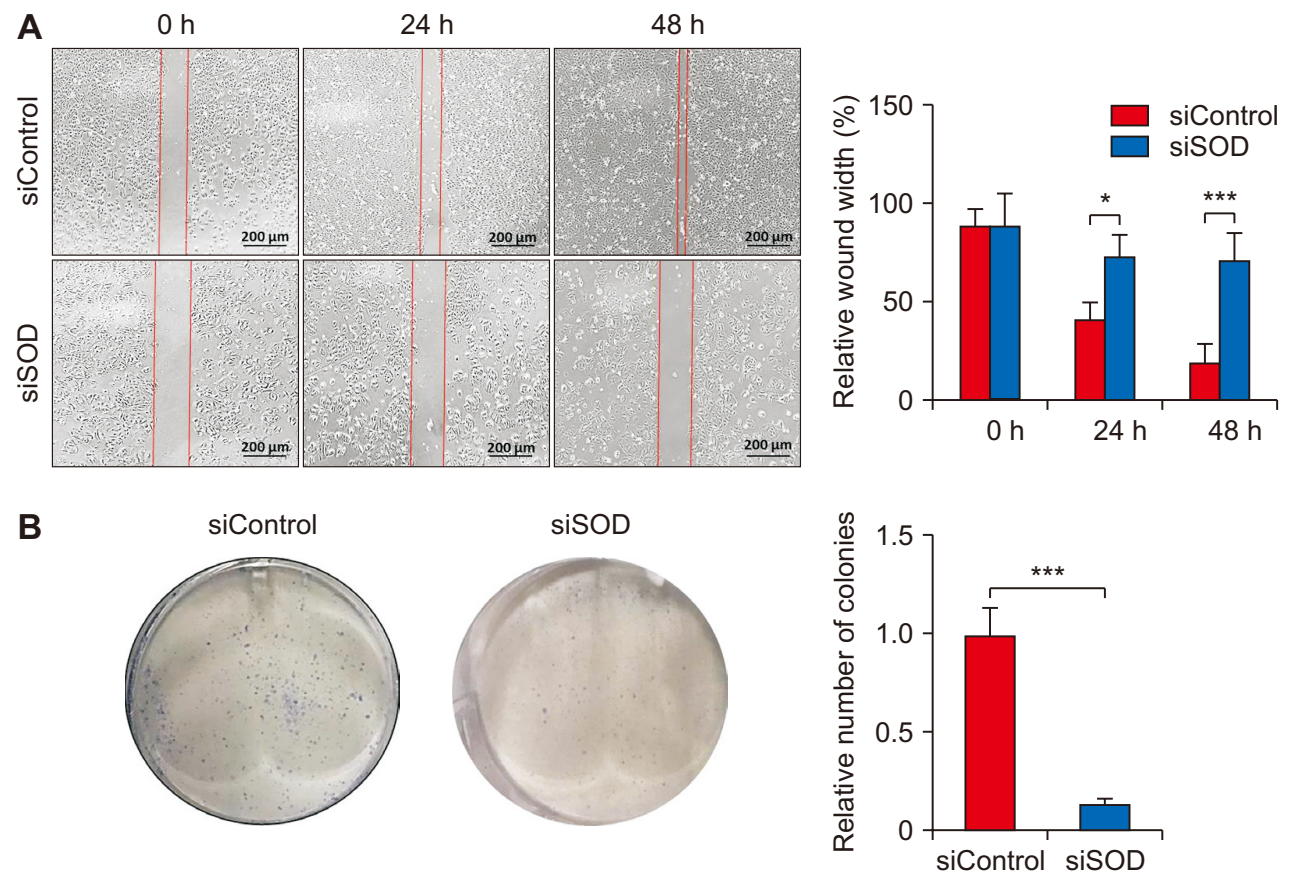

Figure 4. Silencing of manganese superoxide dismutase (MnSOD) abolishes the migrative capability (A) and clonogenicity of (B) MCF-7 cells. Cells were silenced for the MnSOD gene with specific siRNA and cell migration and colony formation were measured as described in Materials and Methods. "Significantly different between the groups compared $(P<0.05)$; ${ }^{* \star}$ Significantly different between the groups compared $(P<0.001)$.

Receptor-bound heregulin- $\beta 1$ was shown to be transported to the nucleus [29], independent of nuclear receptor translocation. Nuclear heregulin- $\beta 1$ modulated the activity of c-Myc, a critical regulator of cell cycle progression, differentiation, and malignant transformation [29], and also stimulated cancer cell proliferation in vitro [30]. Heregulin- $\beta 1$ was reported to induce metastasis- and angiogenesis-related genes such as MMPs $[5,27]$, VEGF [9,28] and Ang-2 [7]. Although it is obvious that heregulin- $\beta 1$ plays a critical role for the progression of breast carcinormas, its molecular composition and biological functions remain elusive.

In this study, we found that heregulin- $\beta 1$ induced the expression and activity of MnSOD in MCF-7 cells. MnSOD is one of typical antioxidant enzymes, which catalyzes the conversion of superoxide $\left(\mathrm{O}_{2}-\right)$ to hydrogen peroxide. Several lines of evidence suggest that some antioxidative enzymes play a key role in the proliferation and invasiveness of tumor cells as well [31-33]. Hydrogen peroxide, the end-product of SOD, has been recognized as an important messenger in cellular signaling network [34]. There has been some evidence supporting that hydrogen peroxide is involved in up-regulation of MMPs [31]. Because of hydrogen peroxide derived from its catalytic reaction, MnSOD may be involved in growth signaling and increased metastatic potential of cancer cells. In support of this notion, MnSOD was found to be responsible for proliferation and metastatic potential in cancer [16-19] and increased drug resistance in response to anticancer therapies $[21,22]$. Interestingly, estrogen-independent breast cancer cell lines such as MDA-MB231 and SKBR3 exhibit a relatively high level of constitutive MnSOD expression, compared to T47D and MCF-7 which are estrogen-dependent cancer cell lines [20].

Localized in mitochondria, MnSOD may also affect proor anti-apoptotic molecules such as Bcl-2, Bad, and Bax. In line with this notion, we found that heregulin- $\beta 1$ treatment enhanced the clonogenicity and migrative capability of MCF7 cells. Since heregulin- $\beta 1$ increases cell proliferation, while up-regulating MnSOD, there might be some inverse association between MnSOD and apoptosis. Some investigators have reported that MnSOD deficiency induces alteration of p53-mediated pathways in cancer cells [35], while others have suggested that MnSOD inhibits mitochondria-mediated cell death $[36,37]$.

Mitochondria are known to play a role in cancer cell growth and transformation through ROS-releasing metabolic activity [38]. Kattan et al. [20] have demonstrated that accumulation of $\mathrm{H}_{2} \mathrm{O}_{2}$ produced by high-MnSOD level is mainly involved in breast cancer cell growth which was blunted by the antioxidant $\mathrm{N}$-acetyl-L-cysteine. $\mathrm{H}_{2} \mathrm{O}_{2}$, as an important mediator involved in cell proliferation, activates several distinct intracellular signaling cascades required for cell cycle progression in human malignant cells including breast cancer [39]. Considering the important role of MnSOD in metastasis and proliferation, the induction of this antioxidant enzyme is likely to contribute to the oncogenic effects of heregulin- $\beta 1$ on human breast cancer growth and progression. 
It is noticeable that heregulin- $\beta 1$-induced MnSOD expression is mediated by Nrf2. Both human and mouse MnSOD genes harbor a putative $\mathrm{NF}-\kappa \mathrm{B}$ transcription regulatory element $[40,41]$. Also present in the promoter regions of SOD gene are multiple copies of specificity protein-1 [42,43], AP-1 [40], AP-2 [44] and ARE sequences [45]. However, there is paucity of data demonstrating MnSOD expression regulated by Nrf2 transcription factor. Our study suggests that Nrf2 may play a role in the up-regulation of MnSOD induced by heregulin- $\beta 1$ in MCF-7 cells. It is generally accepted that Nrf2 is a transcription factor involved in antioxidant enzyme induction to protect cells against oxidative insults. However, uncontrolled hyperactivation of Nrf2 may provide survival advantage of cancer cells and resistance to anticancer drugs, many of which provoke oxidative stress [46].

It is known that diverse upstream kinases, such as MAPKs $[47,48]$, PKC [49] and PI3K [50], are responsible for regulating activation of transcription factor Nrf2. Our data show that heregulin- $\beta 1$ appears to activate Nrf2 transcription factor through phosphorylative activation of ERK and Akt. ERK activation is likely to impact invasion and migration through multiple mechanisms by influencing transcription of genes involved in cell survival and proliferation, as well as by directly regulating the enzymes that are necessary for cell locomotion [51]. Akt plays an important role in all survival signaling through inactivation of a series of pro-apoptotic proteins [52]. Both Akt and ERK are important mediators of cell survival signal transduction. Therefore, the activation of Akt and ERK by heregulin- $\beta 1$ could explain the positive effect of this growth factor on tumor growth.
In conclusion, heregulin- $\beta 1$ induces activation of Nrf2 via the Akt and ERK signaling pathways leading to up-regulation of MnSOD in MCF-7 cells (Fig. 5). It is noteworthy that MnSOD is up-regulated in heregulin- $\beta 1$-treated MCF-7 cells, because highly metastatic estrogen-independent cells (MDAMB231 and SKBR3) express a significantly higher basal MnSOD level compared to estrogen-dependent human breast cancer cell lines (MCF-7 and T47D) [20]. These findings suggest that the assessment of MnSOD status in breast cancers might be useful during anticancer treatment. Elevated levels of MnSOD may influence the effectiveness of both radiation therapy and anticancer drugs that can generate ROS via redox-cycling. Further studies will be necessary to investigate the role of Nrf2 and MnSOD in the breast cancer metastasis.

\section{ACKNOWLEDGMENTS}

This study was supported by the Global Core Research Center (GCRC) grant (No. 2011-0030001) from the National Research Foundation, Republic of Korea.

\section{CONFLICTS OF INTEREST}

No potential conflicts of interest were disclosed.

\section{SUPPLEMENTARY MATERIALS}

Supplementary materials can be found via https://doi. org/10.15430/JCP.2021.26.1.54.

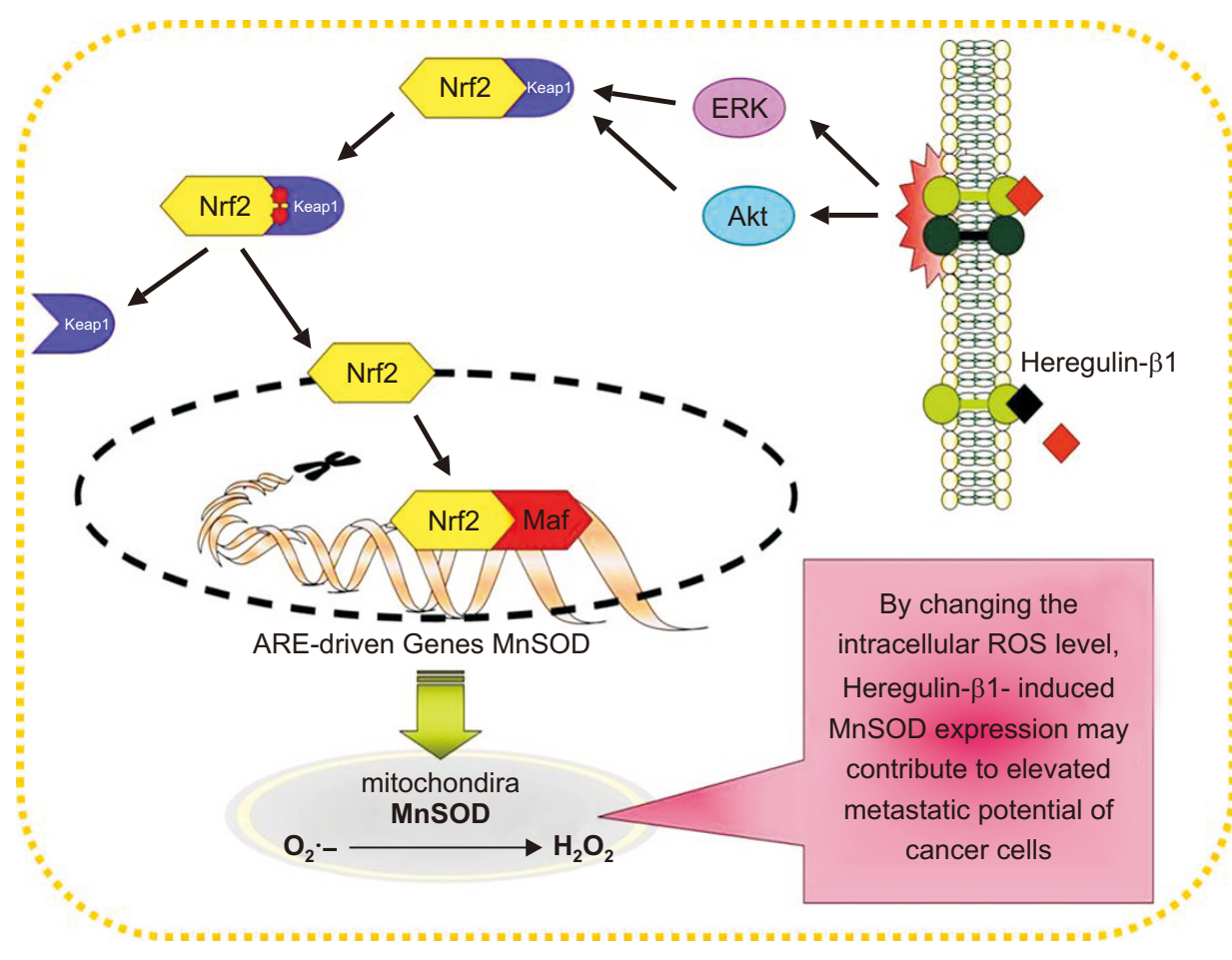

Figure 5. Proposed scheme for the role of heregulin- $\beta 1$ in breast cancer progression. MnSOD, manganese superoxide dismutase; ERK, extracellular signal-regulated protein kinase; Akt, protein kinase B; Nrf2, NF-E2related factor 2; ROS, reactive oxygen species. 


\section{ORCID}

Ji-Young Park, https://orcid.org/0000-0001-8920-6029

Soma Saeidi, https://orcid.org/0000-0002-4943-5596

Eun-Hee Kim, https://orcid.org/0000-0002-8523-0440

Do-Hee Kim, https://orcid.org/0000-0002-9636-8293

Hye-Kyung Na, https://orcid.org/0000-0003-0460-2810

Joo-Seob Keum, https://orcid.org/0000-0002-8617-4823

Young-Joon Surh, https://orcid.org/0000-0001-8310-1795

\section{REFERENCES}

1. Yarden Y. The EGFR family and its ligands in human cancer. signalling mechanisms and therapeutic opportunities. Eur $\mathrm{J}$ Cancer 2001;37 Suppl 4:S3-8.

2. Britsch $\mathrm{S}$. The neuregulin-l/ErbB signaling system in development and disease. Adv Anat Embryol Cell Biol 2007;190:1-65.

3. Burgess TL, Ross SL, Qian YX, Brankow D, Hu S. Biosynthetic processing of neu differentiation factor. Glycosylation trafficking, and regulated cleavage from the cell surface. J Biol Chem 1995;270:19188-96.

4. Lupu R, Cardillo M, Harris L, Hijazi M, Rosenberg K. Interaction between erbB-receptors and heregulin in breast cancer tumor progression and drug resistance. Semin Cancer Biol 1995;6:13545.

5. Yao J, Xiong S, Klos K, Nguyen N, Grijalva R, Li P, et al. Multiple signaling pathways involved in activation of matrix metalloproteinase- 9 (MMP-9) by heregulin- $\beta 1$ in human breast cancer cells. Oncogene 2001;20:8066-74.

6. Hutcheson IR, Knowlden JM, Hiscox SE, Barrow D, Gee JM, Robertson JF, et al. Heregulin beta1 drives gefitinib-resistant growth and invasion in tamoxifen-resistant MCF-7 breast cancer cells. Breast Cancer Res 2007;9:R50.

7. Niu G, Carter WB. Human epidermal growth factor receptor 2 regulates angiopoietin-2 expression in breast cancer via AKT and mitogen-activated protein kinase pathways. Cancer Res 2007;67:1487-93.

8. Tan M, Grijalva R, Yu D. Heregulin $\beta 1$-activated phosphatidylinositol 3-kinase enhances aggregation of MCF-7 breast cancer cells independent of extracellular signal-regulated kinase. Cancer Res 1999;59:1620-5.

9. Tsai PW, Shiah SG, Lin MT, Wu CW, Kuo ML. Up-regulation of vascular endothelial growth factor $C$ in breast cancer cells by heregulin-beta 1. A critical role of p38/nuclear factor-kappa $B$ signaling pathway. J Biol Chem 2003;278:5750-9.

10. Mazumdar A, Adam L, Boyd D, Kumar R. Heregulin regulation of urokinase plasminogen activator and its receptor: human breast epithelial cell invasion. Cancer Res 2001;61:400-5.

11. Boveris A. Mitochondrial production of superoxide radical and hydrogen peroxide. Adv Exp Med Biol 1977;78:67-82.

12. Chuang TC, Liu JY, Lin CT, Tang YT, Yeh MH, Chang SC, et al. Human manganese superoxide dismutase suppresses HER2/neu-mediated breast cancer malignancy. FEBS Lett 2007;581:4443-9.
13. Weydert CJ, Waugh TA, Ritchie JM, lyer KS, Smith JL, Li L, et al. Overexpression of manganese or copper-zinc superoxide dismutase inhibits breast cancer growth. Free Radic Biol Med 2006;41:226-37.

14. Wang M, Kirk JS, Venkataraman S, Domann FE, Zhang HJ, Schafer FQ, et al. Manganese superoxide dismutase suppresses hypoxic induction of hypoxia-inducible factor- $1 \alpha$ and vascular endothelial growth factor. Oncogene 2005;24:8154-66.

15. Ridnour LA, Oberley TD, Oberley LW. Tumor suppressive effects of MnSOD overexpression may involve imbalance in peroxide generation versus peroxide removal. Antioxid Redox Signal 2004;6:501-12.

16. Korenaga D, Yasuda M, Honda M, Nozoe T, Inutsuka S. MnSOD expression within tumor cells is closely related to mode of invasion in human gastric cancer. Oncol Rep 2003;10:27-30.

17. Nozoe T, Honda M, Inutsuka S, Yasuda M, Korenaga D. Significance of immunohistochemical expression of manganese superoxide dismutase as a marker of malignant potential in colorectal carcinoma. Oncol Rep 2003;10:39-43.

18. Izutani R, Asano S, Imano M, Kuroda D, Kato M, Ohyanagi $H$. Expression of manganese superoxide dismutase in esophageal and gastric cancers. J Gastroenterol 1998;33:816-22.

19. Malafa M, Margenthaler J, Webb B, Neitzel L, Christophersen M. $\mathrm{MnSOD}$ expression is increased in metastatic gastric cancer. $\mathrm{J}$ Surg Res 2000;88:130-4.

20. Kattan Z, Minig V, Leroy P, Dauça M, Becuwe P. Role of manganese superoxide dismutase on growth and invasive properties of human estrogen-independent breast cancer cells. Breast Cancer Res Treat 2008;108:203-15.

21. Guo G, Yan-Sanders Y, Lyn-Cook BD, Wang T, Tamae D, Ogi $\mathrm{J}$, et al. Manganese superoxide dismutase-mediated gene expression in radiation-induced adaptive responses. Mol Cell Biol 2003;23:2362-78.

22. Kinnula VL, Pietarinen-Runtti P, Raivio K, Kahlos K, Pelin $\mathrm{K}$, Mattson $\mathrm{K}$, et al. Manganese superoxide dismutase in human pleural mesothelioma cell lines. Free Radic Biol Med 1996;21:527-32.

23. Spitz DR, Oberley LW. An assay for superoxide dismutase activity in mammalian tissue homogenates. Anal Biochem 1989;179:8-18.

24. Cullen JJ, Weydert C, Hinkhouse MM, Ritchie J, Domann FE, Spitz D, et al. The role of manganese superoxide dismutase in the growth of pancreatic adenocarcinoma. Cancer Res 2003;63:1297-303.

25. Chen C, Kong AN. Dietary chemopreventive compounds and ARE/EpRE signaling. Free Radic Biol Med 2004;36:1505-16.

26. Slamon DJ, Clark GM, Wong SG, Levin WJ, Ullrich A, McGuire WL. Human breast cancer: correlation of relapse and survival with amplification of the HER-2/neu oncogene. Science 1987;235:177-82.

27. Tsai MS, Shamon-Taylor LA, Mehmi I, Tang CK, Lupu R. Blockage of heregulin expression inhibits tumorigenicity and metastasis of breast cancer. Oncogene 2003;22:761-8.

28. Atlas E, Cardillo M, Mehmi I, Zahedkargaran H, Tang C, Lupu 
R. Heregulin is sufficient for the promotion of tumorigenicity and metastasis of breast cancer cells in vivo. Mol Cancer Res 2003;1:165-75.

29. Li W, Park JW, Nuijens A, Sliwkowski MX, Keller GA. Heregulin is rapidly translocated to the nucleus and its transport is correlated with c-myc induction in breast cancer cells. Oncogene 1996;12:2473-7.

30. Holmes WE, Sliwkowski MX, Akita RW, Henzel WJ, Lee J, Park JW, et al. Identification of heregulin, a specific activator of p185erbB2. Science 1992;256:1205-10.

31. Brenneisen P, Briviba K, Wlaschek M, Wenk J, ScharffetterKochanek K. Hydrogen peroxide $\left(\mathrm{H}_{2} \mathrm{O}_{2}\right)$ increases the steadystate mRNA levels of collagenase/MMP-1 in human dermal fibroblasts. Free Radic Biol Med 1997;22:515-24.

32. Mori K, Shibanuma M, Nose K. Invasive potential induced under long-term oxidative stress in mammary epithelial cells. Cancer Res 2004;64:7464-72.

33. Nelson KK, Melendez JA. Mitochondrial redox control of matrix metalloproteinases. Free Radic Biol Med 2004;37:768-84.

34. Rhee SG. Cell signaling. $\mathrm{H} 2 \mathrm{O} 2$, a necessary evil for cell signaling. Science 2006;312:1882-3.

35. Zhao Y, Oberley TD, Chaiswing L, Lin SM, Epstein CJ, Huang $\mathrm{TT}$, et al. Manganese superoxide dismutase deficiency enhances cell turnover via tumor promoter-induced alterations in AP-1 and p53-mediated pathways in a skin cancer model. Oncogene 2002;21:3836-46.

36. Kiningham KK, Oberley TD, Lin S, Mattingly CA, St Clair DK. Overexpression of manganese superoxide dismutase protects against mitochondrial-initiated poly(ADP-ribose) polymerasemediated cell death. FASEB J 1999;13:1601-10.

37. Djavaheri-Mergny M, Javelaud D, Wietzerbin J, Besançon F. NF-kappaB activation prevents apoptotic oxidative stress via an increase of both thioredoxin and MnSOD levels in TNFalphatreated Ewing sarcoma cells. FEBS Lett 2004;578:111-5.

38. Grandemange S, Seyer P, Carazo A, Bécuwe P, Pessemesse $\mathrm{L}$, Busson $\mathrm{M}$, et al. Stimulation of mitochondrial activity by $\mathrm{p} 43$ overexpression induces human dermal fibroblast transformation. Cancer Res 2005;65:4282-91.

39. Halliwell B. Oxidative stress and cancer: have we moved forward? Biochem J 2007;401:1-11

40. Kaneko M, Takahashi T, Niinuma Y, Nomura Y. Manganese superoxide dismutase is induced by endoplasmic reticulum stress through IRE1-mediated nuclear factor (NF)-KB and AP-1 activation. Biol Pharm Bull 2004;27:1202-6.
41. Dhar SK, Lynn BC, Daosukho C, St Clair DK. Identification of nucleophosmin as an NF-kB co-activator for the induction of the human SOD2 gene. J Biol Chem 2004;279:28209-19.

42. Xu Y, Porntadavity S, St Clair DK. Transcriptional regulation of the human manganese superoxide dismutase gene: the role of specificity protein 1 (Sp1) and activating protein-2 (AP-2). Biochem J 2002;362(Pt 2):401-12.

43. Daosukho $\mathrm{C}$, Kiningham $\mathrm{K}$, Kasarskis EJ, Ittarat W, St Clair DK. Tamoxifen enhancement of TNF- $\alpha$ induced MnSOD expression: modulation of NF-kappaB dimerization. Oncogene 2002;21:3603-10.

44. Meyrick B, Magnuson MA. Identification and functional characterization of the bovine manganous superoxide dismutase promoter. Am J Respir Cell Mol Biol 1994;10:113-21.

45. Pi J, Qu W, Reece JM, Kumagai Y, Waalkes MP. Transcription factor Nrf2 activation by inorganic arsenic in cultured keratinocytes: involvement of hydrogen peroxide. Exp Cell Res 2003;290:234-45.

46. Hayes JD, McMahon M. The double-edged sword of Nrf2: subversion of redox homeostasis during the evolution of cancer. Mol Cell 2006;21:732-4.

47. Kong AN, Owuor E, Yu R, Hebbar V, Chen C, Hu R, et al. Induction of xenobiotic enzymes by the MAP kinase pathway and the antioxidant or electrophile response element (ARE/EpRE). Drug Metab Rev 2001;33:255-71.

48. Chen C, Yu R, Owuor ED, Kong AN. Activation of antioxidantresponse element (ARE), mitogen-activated protein kinases (MAPKs) and caspases by major green tea polyphenol components during cell survival and death. Arch Pharm Res 2000;23:605-12.

49. Huang HC, Nguyen T, Pickett CB. Regulation of the antioxidant response element by protein kinase $\mathrm{C}$-mediated phosphorylation of NF-E2-related factor 2. Proc Natl Acad Sci USA 2000;97:12475-80.

50. Lee JM, Hanson JM, Chu WA, Johnson JA. Phosphatidylinositol 3-kinase, not extracellular signal-regulated kinase, regulates activation of the antioxidant-responsive element in IMR-32 human neuroblastoma cells. J Biol Chem 2001;276:20011-6.

51. Sebolt-Leopold JS, Herrera R. Targeting the mitogen-activated protein kinase cascade to treat cancer. Nat Rev Cancer 2004;4:937-47.

52. Scheid MP, Woodgett JR. Unravelling the activation mechanisms of protein kinase B/Akt. FEBS Lett 2003;546:108-12. 